\title{
Flora Farallonensis I: los helechos del bosque premontano de Pico de Águila
}

\author{
Flora farallonensis I: The Ferns of Pico de Águila Premontane Forest
}

\author{
Miguel Ángel Gamboa Gaitán \\ Biólogo de la Universidad del Valle, M. Sc. Universidad de Puerto Rico \\ Laboratorio de Biología Tropical, Departamento de Biología, Facultad de Ciencias, \\ Universidad Nacional de Colombia, Colombia \\ https://orcid.org/0000-0002-8145-8712 \\ magamboaga@unal.edu.co
}

\section{RESUMEN}

Este manuscrito inaugura una serie de artículos sobre la flora de los Farallones de Cali, proyecto botánico que pretende dar a conocer el inventario de la flora de esta región, así como estudiar su potencial para la bioprospección del recurso natural florístico. Este escrito aborda los helechos hallados en la vereda Pico de Águila, departamento del Valle, presentando sus descripciones, datos biogeográficos y algunas ilustraciones que facilitan su identificación.

Palabras clave: flora neotropical, Colombia, pteridófitas, Farallones de Cali.

\section{ABSTRACT}

This manuscript is the first of a series of papers dedicated to study flora in Los Farallones de Cali National Park, in Colombia. The purpose of this research is to make an inventory of plant species in this national park, showing their local distribution and selecting potential useful species for bioprospection analysis. This paper deals with pteridophytes species at Pico de Águila (Valle) and includes the first illustrated record of ferns at Los Farallones.

Keywords: Neotropical flora, Colombia, pteridophytes, Farallones de Cali. 


\section{INTRODUCCIÓN}

La Flora de los Farallones de Cali es un proyecto ambicioso que está en mora de haberse iniciado, particularmente por el hecho que en Colombia existe una larga tradición botánica sustentada por un gran número de excelentes profesionales en esta disciplina. Algunos aspectos que retrasaron su inicio fueron los temas de orden público y la poca financiación para proyectos científicos de biodiversidad. Una vez tomada la decisión de embarcarse en este megaproyecto surgen preguntas tales como: ¿qué clase de organismos deberían ser incluidos en una flora?, ¿cómo organizar esta obra?, ¿cuál es el límite geográfico de Los Farallones?

Esta flora de los Farallones se irá publicando en contribuciones puntuales en revistas científicas, para luego hacer volúmenes independientes que estarán dedicados a sitios específicos de los Farallones de Cali, los cuales estarán constituidos por tomos dedicados a diferentes grupos de plantas. El proyecto se llevará a cabo de esta manera debido a que un muestreo completo del parque es prácticamente imposible en la actualidad a causa de la situación de orden público en algunas partes del parque y a la inaccesibilidad del terreno en otras, para lo cual sería necesario realizar costosas excursiones de muestreo. Considerando lo anterior, resulta imposible presentar completamente un solo grupo de plantas de los Farallones, por ejemplo, las Solanaceae o las Orchidaceae, tal como se hace tradicionalmente en las floras de los países, por lo que ir muestreando localidades puntuales de este ecosistema parece una estrategia más razonable en las condiciones actuales.

Este trabajo permitirá que la flora propia de este parque nacional sea conocida de manera progresiva, lo cual quizá aumente las probabilidades de conseguir financiación para el estudio de lugares remotos, como la ladera occidental de los Farallones de Cali. Los grupos que serán incluidos en toda la obra son algas, hongos, briófitas, pteridófitas y espermatófitas. Dentro de cada uno de estos grupos se llevará una organización alfabética por familias, haciendo de cada una de ellas un breve diagnóstico basado en literatura relevante en el área y en los ejemplares reportados en el lugar muestreado.

Es pertinente dar una explicación acerca de por qué se ha decidido constituir la obra de esta manera. Al- gas, hongos y vegetación terrestre eran los organismos que constituían el reino vegetal -o reino de las plantas- hasta hace poco tiempo. Su inmovilidad, su capacidad fotosintética (en las algas) y el hecho de que casi siempre conviven estrechamente con la vegetación terrestre, llevó a que las algas, los hongos y los líquenes fueran tradicionalmente estudiados por los botánicos, quienes los consideraban elementos de la flora de cualquier lugar. Sin embargo, modernos estudios taxonómicos muestran que estos grupos no pueden ser sostenidos en el mismo reino si se quiere realizar una clasificación basada en los principios filogenéticos. En efecto, las algas son en realidad un conjunto polifilético de protistas que debió ser deshecho para reasignar varios de sus taxones en diversos reinos de eucariotas. Solo las algas verdes se mantuvieron cercanamente emparentadas con las plantas terrestres. Si bien las algas son hoy día estudiadas por su propia disciplina, la ficología, es claro que se recolectan, tratan y almacenan de manera similar a las plantas en los herbarios, razón por la cual siguen siendo parte del quehacer botánico. Adicionalmente, las algas tienen una taxonomía complicada y se conoce muy poco de las especies tropicales, particularmente de las especies de ecosistemas montañosos. Todo esto justifica que las algas verdes sean estudiadas en esta obra.

En cuanto a los hongos, se puede decir que forman un reino separado de las plantas, en realidad más cercanamente emparentado con el reino animal que con el vegetal. Por ello, estas especies deberían ser incluidas en los estudios de fauna, más que en los de la flora de los ecosistemas. Sin embargo, los zoólogos no parecen interesados en incluir a los hongos en los libros de zoología ni en los inventarios de fauna; mucho menos en tomar las colecciones fúngicas de los herbarios para ubicarlas en los museos zoológicos. Por ello, los hongos siguen siendo tema de la botánica sensu lato, y aunque se violan los principios filogenéticos, se ha decidido atender a la tradición e incluir a los hongos en esta Flora de Los Farallones de Cali.

Además de las algas y los hongos, esta Flora Farallonensis también incluirá la vegetación terrestre, la cual forma el grueso de la diversidad vegetal. Las plantas terrestres serán presentadas en los grandes grupos que tradicionalmente son usados para estudios a nivel de pregrado: i) plantas avasculares o briófitas, ii) plantas vasculares sin semilla o pteridófitas y iii) plantas 
con semilla o espermatófitas. Para su presentación se tendrá como referencia el conjunto de autores en sistemática vegetal de obligatoria consulta, Cronquist, Takhtajan, Thorne, Dahlgren, Kubitski y Judd, entre otros, pero a la vez se prestará mucha atención a las publicaciones especializadas más recientes cuando se pretenda establecer a qué categoría taxonómica pertenece una especie determinada.

Aunque en la actualidad existen propuestas que modifican la posición de algunos grupos grandes de plantas, resulta más didáctico presentar la flora en la forma tradicional, debido a que dichas propuestas generalmente afectan a los taxones superiores y no a las categorías por debajo de familia, y a que su validez es un asunto aún en discusión. En esta obra se ha optado por ubicar las especies halladas en cada uno de los grandes grupos tradicionales. De ser necesario, se mencionará la referencia que propone su nueva ubicación para que la persona interesada pueda llevar a cabo la consulta correspondiente.

\section{MATERIALES Y MÉTODOS}

\section{Sitio de estudio}

El sitio de estudio es conocido bajo el nombre de Farallones de Cali, una región biogeográfica interesante que se localiza en la Cordillera Occidental del sistema andino colombiano. Si bien su epicentro es el Parque Nacional Natural Los Farallones de Cali (PNNFC), que actualmente forma parte del Sistema de Parques Nacionales Naturales de Colombia, el ecosistema natural que representan los Farallones de Cali no puede limitarse únicamente a la zona bajo protección estatal. Los extensos territorios aledaños al parque, con los que existe una continuidad biológica natural, constituyen importantes zonas de amortiguación que se caracterizan también por poseer una gran diversidad de especies.

El PNNFC fue creado en 1968 y actualmente se encuentra bajo la jurisdicción del Ministerio de Ambiente, Vivienda y Desarrollo Territorial y de la Corporación Autónoma Regional del Valle (Cvc); desde aquella época, el estado de conservación de esta zona ha mejorado considerablemente. Antes de la creación del área de protección oficial, los Farallones eran usados como fuente de variados recursos naturales que se extraían inadecuadamente mediante actividades como la minería, la caza y la tala de bosques. La vegetación estaba bajo fuerte presión extractiva, ya que tanto especies ornamentales como maderables fueron selectivamente sacadas del parque desde que la ciudad de Santiago de Cali se estableció en su ladera oriental. Algunos ejemplos de especies ornamentales extraídas sin control de los Farallones son los anturios, los helechos y las orquídeas, mientras que entre las especies maderables más usadas se puede mencionar el comino, el mediocomino, el laurel, el roble negro y el laurel amarillo.

EI PNNFC es considerado una zona de muy alta prioridad en materia de conservación y con alta vulnerabilidad a la invasión humana (García-Kirkbride, 1986) debido a los numerosos asentamientos que se han establecido a sus alrededores. Si bien sus suelos son clasificados como de fertilidad baja y muy baja (CVC, 1983), el avance de colonos, el establecimiento de potreros para ganadería extensiva, la parcelación de terrenos para vivienda, la minería y la extracción de madera son factores que hoy día amenazan la integridad de los Farallones.

Geográficamente, el parque abarca territorios en los municipios de Cali, Jamundí, Dagua y Buenaventura (figura 1), en el departamento del Valle del Cauca, con una superficie de 205.266 hectáreas y un rango altitudinal entre 200 y $4.100 \mathrm{~m}$, siendo sus coordenadas extremas $3^{\circ} 39^{\prime} 55,5^{\prime \prime}-3^{\circ} 6^{\prime} 56,7^{\prime \prime}$ de latitud norte $y$ $77^{\circ} 6^{\prime} 6,69^{\prime \prime}-77^{\circ} 35^{\prime} 43,6^{\prime \prime}$ de longitud oeste (Sarria, 1993; PNNC, 2005, 2007).

En esta Flora de los Farallones de Cali, sin embargo, el sitio de estudio será delimitado en un sentido un tanto diferente, pues además del área oficialmente adscrita al parque, los territorios que presenten continuidad florística también serán incluidos. Es por ello que varios tomos de la obra estarán dedicados a flórulas ubicadas por fuera del área oficial del PNNFC, pero que muestran continuidad biológica con él. De tal forma, esta obra pretende abordar a los Farallones de Cali como una unidad natural, por lo que es importante entender que los Farallones es, ante todo, un ecosistema montañoso dentro del sistema cordillerano Andino. Razón por la cual su flora es básicamente de montaña.

A partir de lo anterior, el alcance de esta obra en términos biogeográficos debe establecerse altitudinalmente en ambas laderas de los Farallones. En la ladera 
Figura 1. Mapa de la ubicación geográfica aproximada del Parque Nacional Natural Los Farallones de Cali

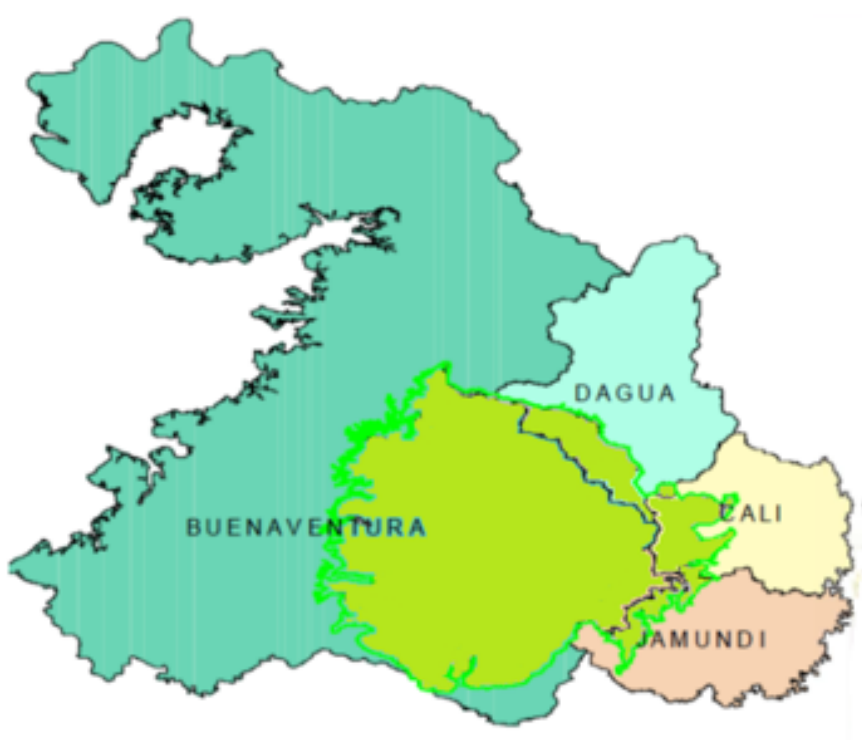

Fuente: CVC 1983

occidental de la Cordillera Occidental de Colombia, la cota de los $1.100 \mathrm{~m}$ ha sido establecida como el límite altitudinal máximo de la región de la costa pacífica colombiana (Rangel et al., 1995), punto en el que se empieza a evidenciar la diferencia ente la flora de la Ilanura costera del pacífico (que forma parte del Chocó biogeográfico) y la flora de la vertiente occidental de los Farallones (que forma parte del sistema montañoso andino). En la ladera oriental de la Cordillera Occidental el límite de los Farallones debe establecerse en el punto en que se da la transición floral entre los ecosistemas de montaña y los ecosistemas secos y semisecos del valle geográfico del río Cauca, límite que puede ser también ubicado a $1.100 \mathrm{~m}$. En efecto, el trabajo de Mahecha-Vega y Echeverri-Restrepo (1983) sobre los árboles del Valle del Cauca usa esta cota como el límite superior del valle geográfico del río Cauca en el departamento del Valle.

Las primeras contribuciones a esta Flora Farallonensis, que se inauguran con este artículo sobre pteridófitas, estarán dedicadas a la flórula del bosque hallado en las inmediaciones de la vereda Pico de Águila, corregimiento de Pance, municipio de Santiago de Cali. Dicha vereda es un pequeño caserío de unas 20 familias (alrededor de 80 personas), ubicadas en la ladera oriental de los Farallones en la zona de amortiguación que rodea al parque y que lo separa de Cali y Jamundí (figura 2). Pico de Águila se localiza a una altitud de $1.550 \mathrm{~m}$, con una temperatura media anual en el rango 18-24 ㄷ, cuyo ecosistema corresponde a la zona del bosque muy húmedo subtropical, según Espinal (1968), quizá más correctamente descrito como bosque tropical montano bajo, con clima tropical Iluvioso de bosque, ubicado en pleno piso térmico medio (CVC, 2010). El único trabajo florístico realizado en la zona es el de Gamboa-Gaitán (1995), el cual constituye, junto con nuevas recolecciones de material vegetal realizadas a partir de 2009 , la base de esta y las próximas publicaciones.

Es importante anotar que la zona original en la que se realizó el estudio, la cual comprendía un área aproximada de seis hectáreas (Gamboa \& Ramos, 1995), fue inmensamente intervenida hacia el año 2003 debido a invasiones por parte de colonos como consecuencia de las alteraciones de orden público en la región. Actualmente, casi todos los predios que se formaron en esa época están abandonados, por lo que se está dando el proceso de regeneración natural. Dichas invasiones alteraron sustancialmente la composición florística de la zona y es factible decir que en ella se dio tanto el fenómeno de fragmentación de bosques como el de extinción local, puesto que no se han encontrado algunas de las especies reportadas en los estudios de 1995. Por ello, es posible que algunas de las descripciones dadas en este y los siguientes trabajos se basen solamente en un individuo, quizá ya extinto, cuya muestra botánica muy probablemente se encuentra en el Herbario de la Universidad del Valle (cuvc), aun cuando existen algunos duplicados en el Herbario Nacional Colombiano (COL).

\section{Recolección e identificación}

Las especies estudiadas fueron recolectadas de manera discontinua desde 1994 hasta el presente. El proceso de muestreo continúa, pues es posible que existan especies que no hayan sido recolectadas, especialmente aquellas en las partes altas del dosel, como se ha evidenciado con otros grupos de angiospermas como las briófitas y las orquídeas, entre las cuales siguen apareciendo nuevos registros. El material recolectado fue depositado en bolsas plásticas individuales con un número de recolección bajo el cual se apuntan sus datos en la bitácora. Luego, estos son llevados al sitio de ordenamiento de las muestras, si- 
Figura 2. Mapa de la ubicación de Pico de Águila en las cercanías de los Farallones de Cali (estrella en el mapa de la izquierda)

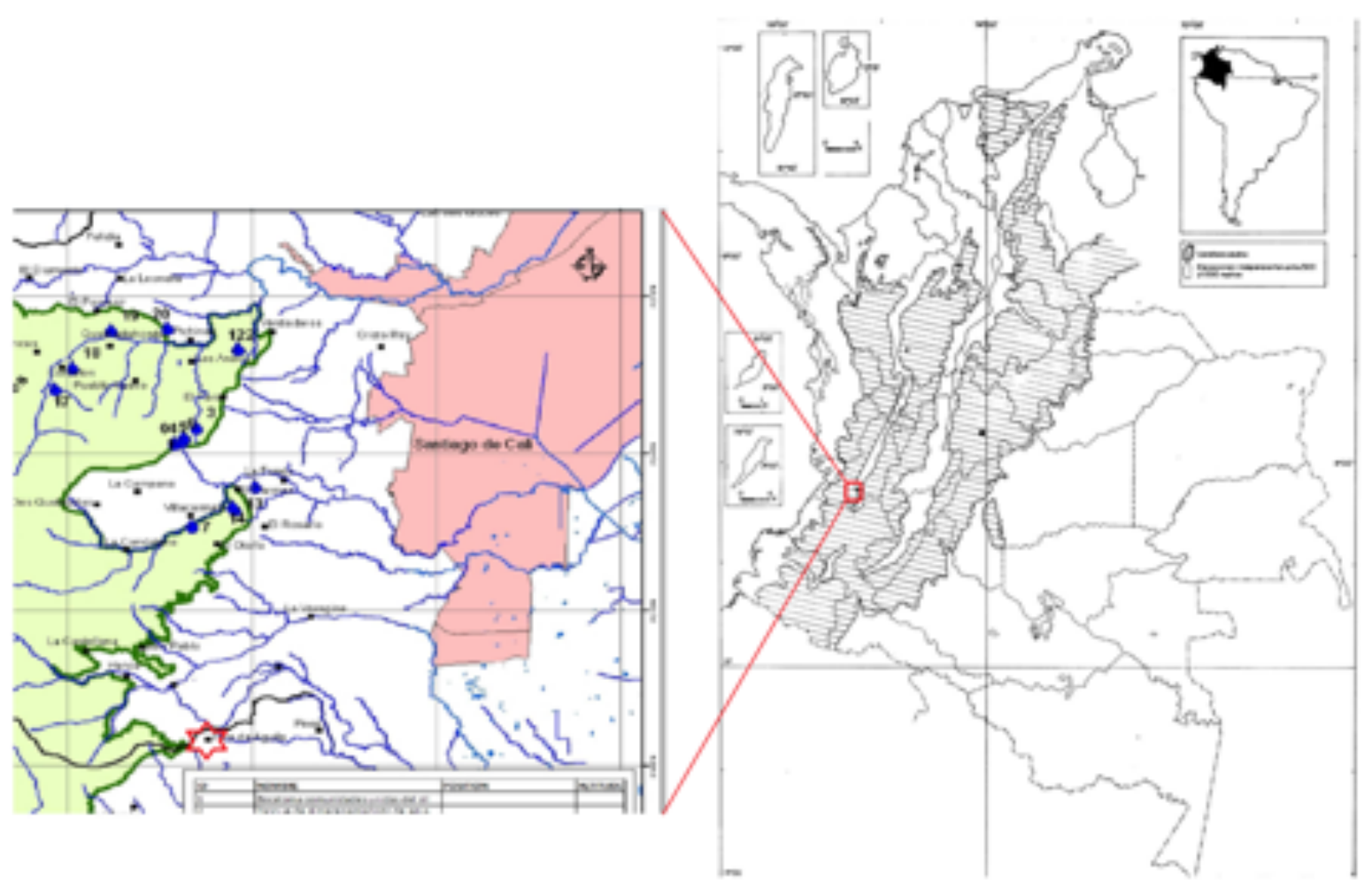

Fuente: PNNC 2007 y Departamento de Biología, Universidad Nacional de Colombia.

tuado en la finca Nazaret de la vereda Pico de Águila, donde sus propietarios, Teodoro Valencia y su esposa, permitieron llevar a cabo el procesamiento de las muestras. Allí, estas fueron puestas en papel periódico con su respectivo número de colección y posteriormente fueron prensadas para ser transportadas al cuvc o al Laboratorio de Biología Tropical, donde fueron secadas en prensa metálica a $70 \stackrel{\circ}{C}$ durante al menos 24 horas. Una vez seco, el material fue contado en cartulina libre de ácido y dispuesto para su identificación por parte de especialistas. Todas las especies identificadas aquí presentadas fueron ilustradas por el autor antes de ser secadas al horno. En la actualidad, se sigue visitando el lugar en búsqueda de nuevas especies y para recoger información sobre sus usos, con lo cual se busca identificar taxones con potencial para investigaciones futuras en el campo de la bioprospección.

\section{RESULTADOS}

Las pteridófitas son plantas terrestres que tienen en común dos características notables: un sistema vascular bien desarrollado y la ausencia de semilla. Tra- dicionalmente, atendiendo principalmente fines didácticos, estas han sido divididas en psilotales, licopodios, equisetos y helechos, grupos ubicados en diferentes categorías a lo largo del desarrollo de la sistemática vegetal, desde orden hasta división. Sin embargo, propuestas recientes cambian la posición de algunos taxones de pteridófitas con respecto a algunas plantas fósiles y a las plantas con semilla, haciendo que el grupo sea insostenible porque no es monofilético (figura 3). Por ejemplo, una familia de los grupos eusporangiados de los helechos tradicionales (Ophioglossaceae) parece más emparentada con los psilotales que con otros helechos, mientras que los equisetos parecen estar mejor agrupados con los helechos leptosporangiados (Judd et al., 2007).

A pesar de las inconsistencias sistemáticas a nivel de categorías superiores, las familias de las pteridófitas están relativamente bien delimitadas. Kramer \& Green (1990), propusieron 38 familias: 1 familia en psilotales, 1 en equisetales, 3 en licopodios y 33 en los helechos. Dieciséis años después, Smith et al. (2006) separaron los licopodios de los verdaderos helechos y aceptaron la existencia de 37 familias (1 en psilotales, 1 en equisetos, 2 eusporangiadas y 33 en los helechos 
leptosporangiados). Debe enfatizarse aquí que la separación de los licopodios (licófitas) de los helechos verdaderos (monilófitas), es lo que hace a las pteridófitas un grupo parafilético (figura 3), de acuerdo con Raubeson y Jansen (1992), Pryer et al. (2001) y Smith et al. (2006). Sin embargo, Christenhusz, Zhang y Schneider (2011), proponen una agrupación lineal de licopodios y helechos con un total de 48 familias, por lo que es claro que seguir usando dicho término es de utilidad botánica, ya que las pteridófitas, en sentido tradicional, son un grupo de plantas con notables similitudes morfoanatómicas y ecológicas, lo cual facilita y justifica su estudio como un grupo unificado. Más recientemente Christenhusz y Chase (2014), hacen una propuesta más incluyente que trata de evitar el uso excesivo de familias y géneros, en la cual pro- ponen tres familias para los licopodios y 21 familias de helechos, a los cuales subdividen en cuatro subclases.

Es claro que la sistemática de las pteridófitas sensu lato es un tema altamente dinámico, por lo que resulta necesario establecer claramente qué postura se sigue cuando se presentan plantas en este grupo. En esta obra se ha decidido presentar a los helechos aceptando a Blechnum y Thelypteris en sus propias familias, siguiendo en este caso la postura de Smith et al. (2006), pero a la vez tratando de hacer más concisas las familias en una posición más cercana a Christenhusz \& Chase (2014), que es probablemente la postura que prevalecerá. Los dos géneros mencionados son muy grandes, lo cual justifica en parte la aceptación de sus propias familias.

Figura 3. Constitución actual del reino vegetal

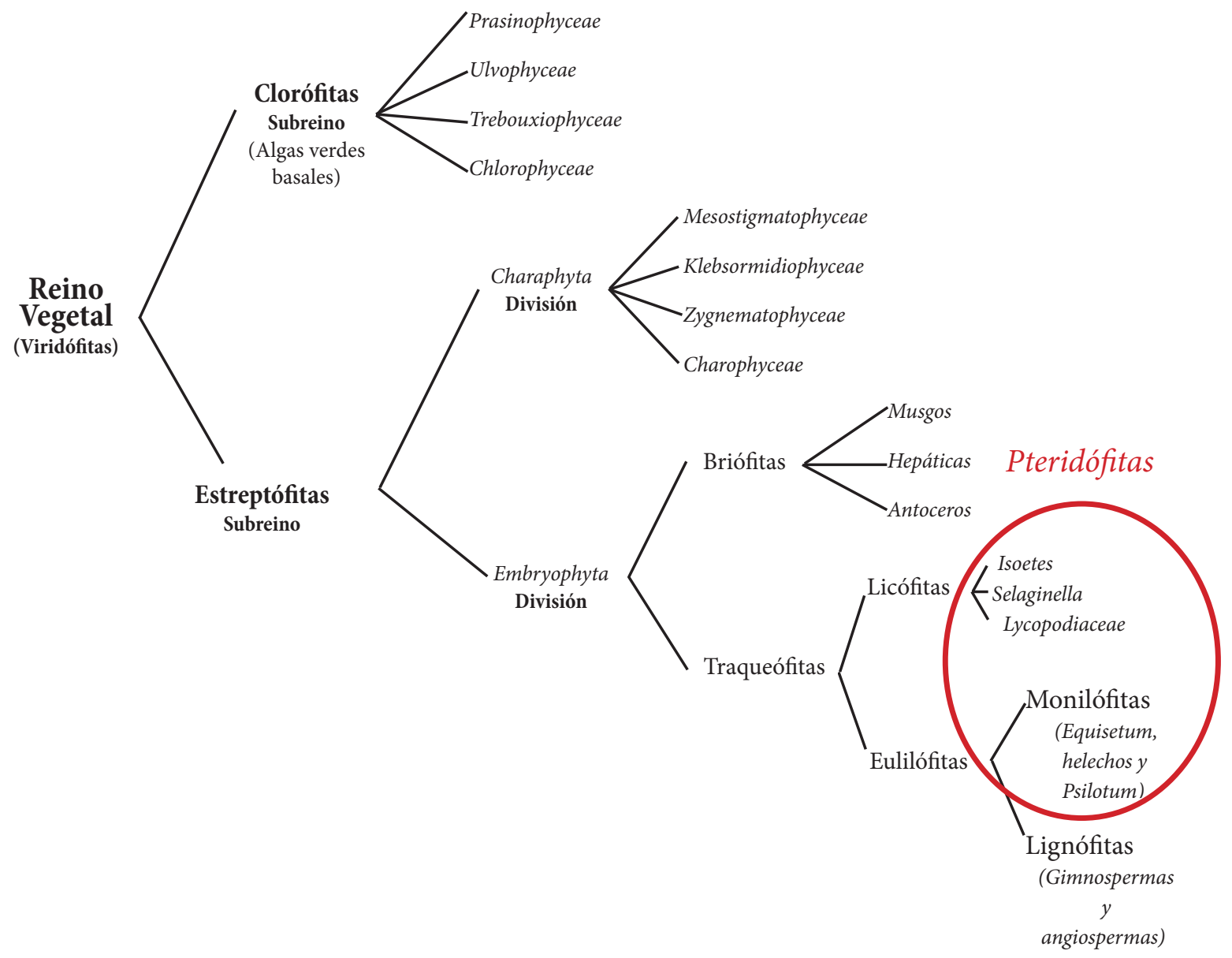

Fuente: elaboración propia. 
En la vereda Pico de Águila de los Farallones de Cali, altitud $1.550 \pm 50 \mathrm{~m}$, se hallaron 18 especies de pteridófitas, todas ellas helechos, distribuidas en 13 géneros de 8 familias, las cuales se describen a continuación en orden alfabético por familias.

\section{Familia Aspleniaceae Newman}

Hierbas terrestres, epilíticas y epífitas, rara vez de más de $1 \mathrm{~m}$ de longitud. Poseen unas 700 especies en un solo género (Asplenium), el cual es de distribución cosmopolita pero con la mayoría de sus especies tropicales y de zonas templadas del hemisferio sur. Se considera que los Andes son un posible centro secundario de diversificación (Kramer \& Viane, 1990). Christenhusz y Chase (2014) consideran que esta familia debe ser entendida en sentido muy amplio e incluyen en ella a Blechnum, Thelypteris y Diplazium, cada uno en diferentes subfamilias.

\section{Asplenium auritum Swartz}

Hierba epífita estrechamente asociada con otras especies de la misma sinusia. Individuos pequeños, con 4-10 frondas de $15-35 \mathrm{~cm}$ de longitud, con pinnas que disminuyen en longitud y se van fusionando desde la base hasta el ápice de la fronda, raquis con un pliegue entre las pinnas. Soros de 2-4 mm de longitud, paralelos a la vena secundaria, rojizos en la madurez, cubren gran parte de la superficie inferior de la pinna, indusio presente. Se ha reportado su uso como planta ornamental y medicinal (Murillo, 1983) (figura 4).

Distribución: Antioquia, Boyacá, Caldas, Caquetá, Cauca, Chocó, Cundinamarca, Huila, Magdalena, Meta, Nariño, Norte de Santander, Putumayo, Quindío, Risaralda, Santander, Tolima, Valle, Vaupés y Vichada, desde el nivel del mar hasta $3.200 \mathrm{~m}$.

Figura 4. Asplenium auritum: A) rizoma y fronda, B) detalle de una pinna fértil

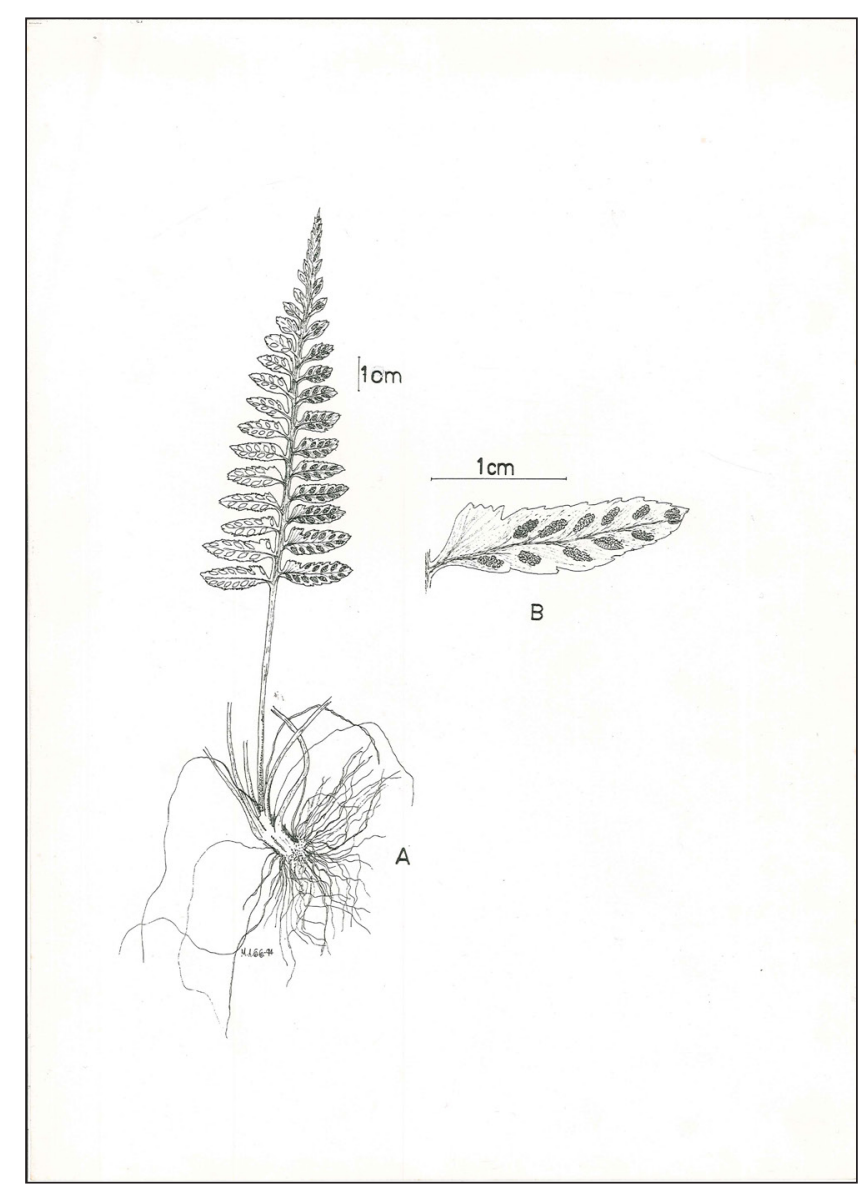

Fuente: elaboración propia. 


\section{Asplenium radicans $\mathrm{L}$.}

Hierba terrestre, crece en zonas sombreadas con abundante hojarasca en el suelo. Frondas de hasta 1 $\mathrm{m}$, con indusio. Al parecer, el espécimen pertenece a la variedad uniseriale (Raddi) Gómez.

Distribución: Antioquia, Boyacá, Caldas, Caquetá, Cauca, Cesar, Chocó, Cundinamarca, Huila, Magdalena, Meta, Nariño, Quindío, Risaralda, Santander, Tolima y Valle, entre 150 y $2.900 \mathrm{~m}$.

\section{Asplenium salicifolium L.}

Hierba terrestre de zonas húmedas y sombreadas. Fronda de $35-50 \mathrm{~cm}$ de longitud, raquis negro con dos canales longitudinales. Pinnas de 2-15 cm, enteras, lobadodentadas, fusionadas en el ápice de la fronda. Soros alargados, con indusio, venación abierta (figura 5).

Distribución: Antioquia, Boyacá, Casanare, Chocó, Cundinamarca, Guajira, Magdalena, Meta, Santander y Valle, entre 680 y $2.500 \mathrm{~m}$.

Figura 5. Asplenium salicifolium: A) ápice de la fronda, B) pinnas, C) rizoma y base de las frondas

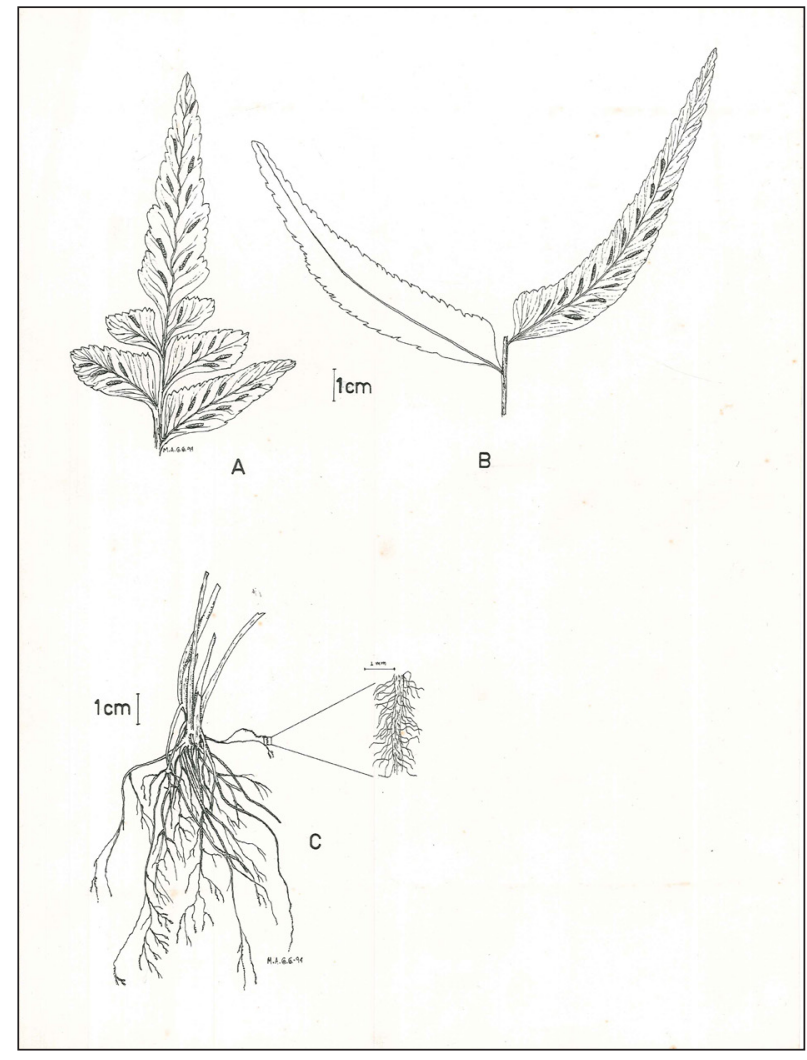

Fuente: elaboración propia.

\section{Diplazium striatum (L.) C. Presl vel sp. aff.}

Smith et al. (2006) consideran que este género debe estar en la familia Woodsiaceae, mientras que Christenhusz et al. (2011) lo ubican en la familia Athyriaceae. Por su parte, Christenhusz y Chase (2014) lo ubican en las aspleniáceas en sentido amplio, en la subfamilia Athyrioideae. Hierba terrestre de $50 \mathrm{~cm}$, localizada en zonas intervenidas del bosque. Raquis con canal longitudinal, pinnas lobadas, ligeramente dentadas, se fusionan hacia el ápice, de $4-22 \mathrm{~cm}$ por 1-4 cm, venación abierta. Soros de 2-6 mm de largo, ubicados sobre las venas secundarias, en dirección al ápice, con indusio (figura 6).

Distribución: Amazonas, Antioquia, Caldas, Cauca, Chocó, Cundinamarca, Huila, Magdalena, Putumayo y Valle, entre 100 y $2.700 \mathrm{~m}$. 
Figura 6. Diplazium striatum: A) pinna fértil vista por el envés, B) rizoma, C) detalle de los soros

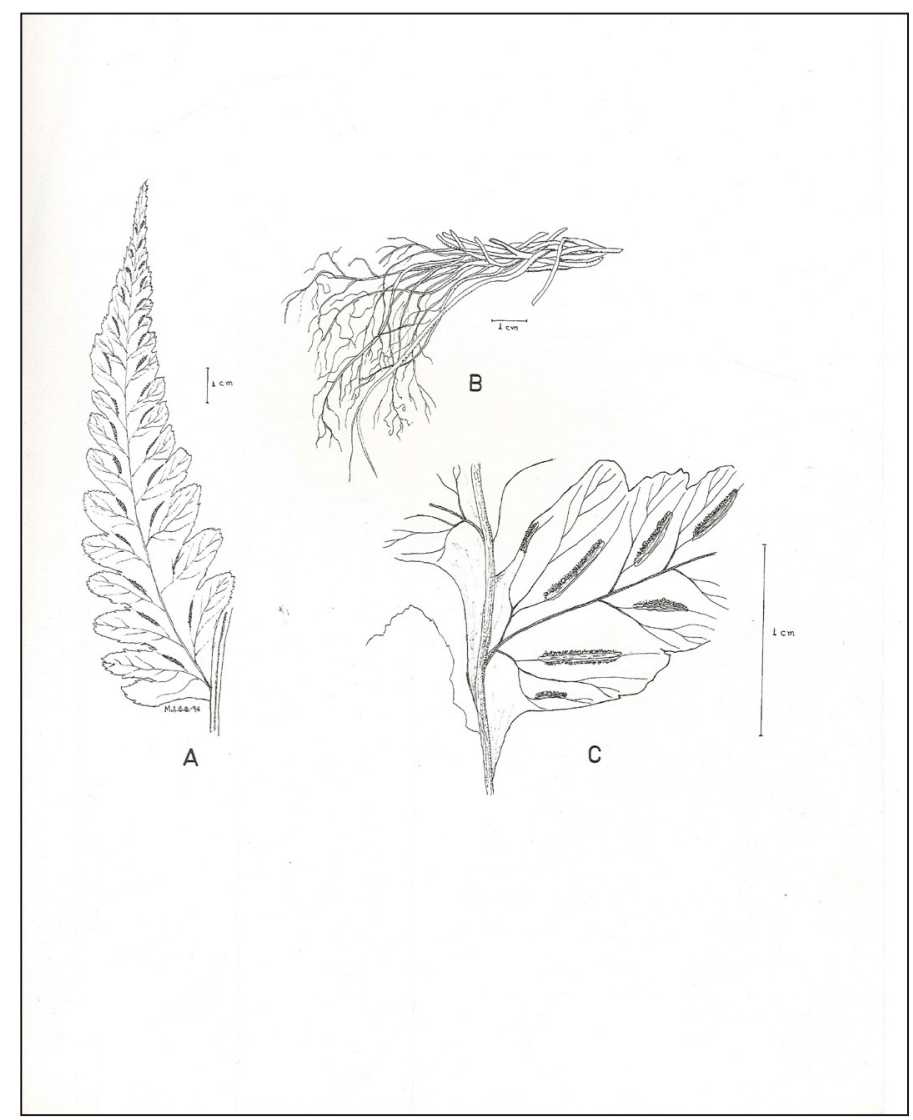

Fuente: elaboración propia.

\section{Familia Blechnaceae (C. Presl) Copel.}

Se trata de hierbas terrestres o epilíticas, rara vez epífitas, que pueden presentar dimorfismo marcado entre frondas estériles y fértiles, raquis y peciolos con surcos. Presente en casi todo el mundo, esta familia tiene unas 250 especies, siendo Blechnum el género más abundante, particularmente conspicuo en el hemisferio sur, donde alcanza a darse en las montañas tropicales. Otros géneros: Brainea, Stenochlaena, Woodwardia (Kramer, Chambers \& Hennipman, 1990). Smith et al. (2006) sostienen que las blechnoideas deben ser consideradas una familia; sin embargo, en la obra de Christenhusz y Chase (2014) aparecen como una subfamilia dentro de Aspleniaceae, grupo que claramente necesita un tratamiento taxonómico extenso.

\section{Blechnum confluens Schlechter \& Chamizo}

Hierba terrestre de zonas húmedas. Frondas de 20-40 $\mathrm{cm}$, pinnas enteras de 1-3 cm, mucronadas, venación abierta, soros lineales paralelos a la vena central, de 4-14 mm, indusio presente (figura 7).

Distribución: Antioquia y Valle, entre 200 y 1.600 m.

\section{Blechnum fraxineum Willdenow}

Hierba terrestre de zonas sombreadas con abundante hojarasca. Frondas $20-45 \mathrm{~cm}$, pinnas lanceoladas, a veces un poco ovaladas de $2-11 \mathrm{~cm}$.

Distribución: Antioquia y Valle, entre 1.030 y 2.000 m. 
Figura 7. Blechnum confluens: A) fronda y rizoma, B) pinnas fértiles

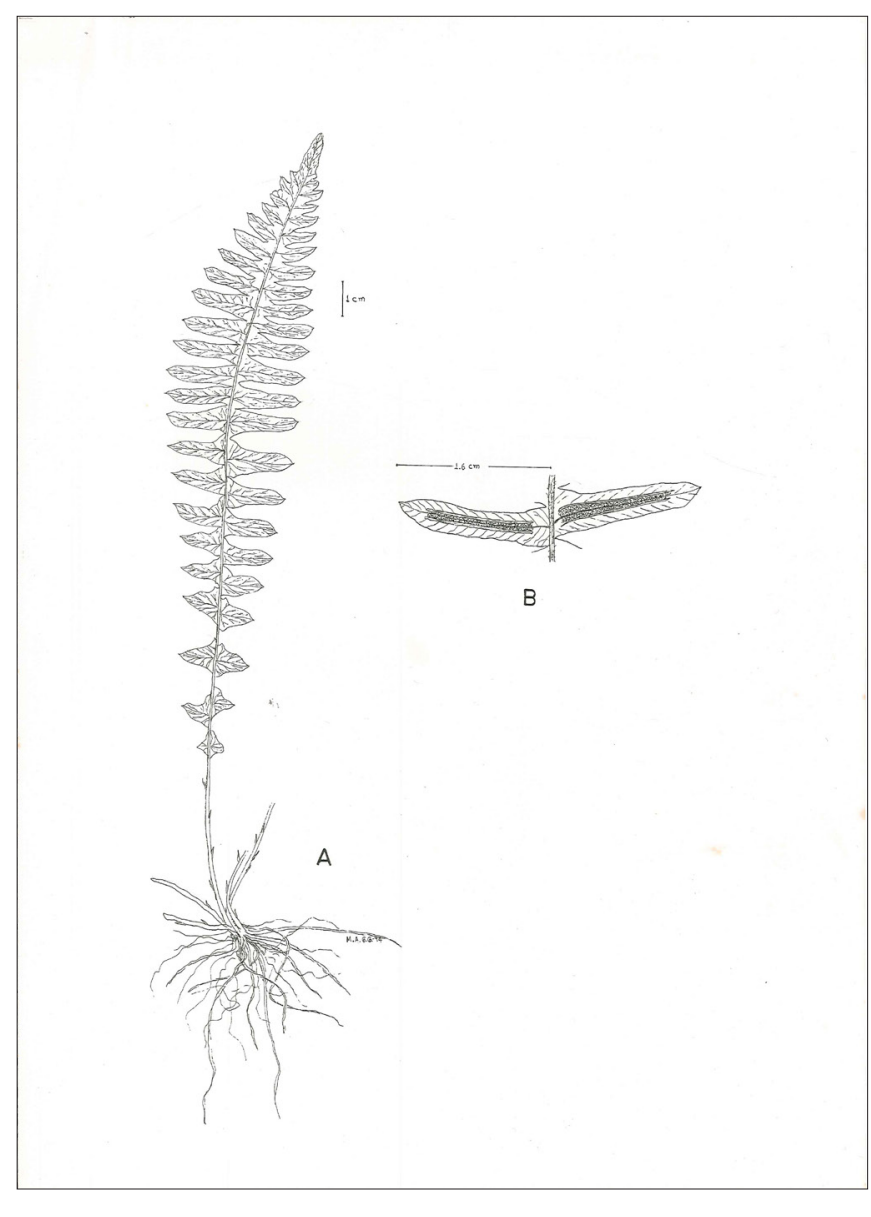

Fuente: elaboración propia.

\section{Blechnum occidentale $\mathrm{L}$.}

Hierba terrestre, común en zonas en regeneración. Frondas de $25-70 \mathrm{~cm}$, con venación abierta, soros alargados a ambos lados de la vena central de la pinna, de 0,4-9,0 cm, se fusionan hacia el ápice, indusio presente. Se ha registrado su uso medicinal en el tratamiento de cálculos (Murillo, 1983) (figura 8).

Distribución: Antioquia, Boyacá, Caldas, Cauca, Cesar, Chocó, Cundinamarca, Guajira, Huila, Magdalena, Meta, Nariño, Norte de Santander, Quindío, Risaralda, Santander, Tolima, Valle y Vaupés, desde el nivel del mar hasta $2.800 \mathrm{~m}$.

\section{Familia Dryopteridaceae Ching}

Hierbas terrestres o epilíticas, rara vez epífitas. Lámina de la fronda a menudo oblonga, soros orbiculares, esporas monoletes y venación abierta. Algunas espe- cies de Dryopteris y de los géneros más emparentados con él han sido estudiadas por la presencia de compuestos venenosos y de uso medicinal (Kramer et al., 1990). Christenhusz y Chase (2014), la consideran una subfamilia dentro de las Polypodiaceae.

\section{Polystichum platyphyllum (Willdenow) C. Presl}

Hierba terrestre, con frondas de hasta $70 \mathrm{~cm}$, raquis verde con canal central, escamas delgadas con pelos de hasta $8 \mathrm{~mm}$, pinnas de 1,0-2,5 cm de longitud soros redondeados, marginales, dispuestos en " $U$ ", venación abierta. Crece en suelos con abundante hojarasca (figura 9).

Distribución: Antioquia, Boyacá, Caldas, Cauca, Cesar, Chocó, Cundinamarca, Quindío, Huila, Magdalena, Meta, Nariño, Putumayo, Risaralda, Tolima, Valle, desde del nivel del mar hasta $2.800 \mathrm{~m}$. 
Figura 8. Blechnum occidentale: A) ápice de una fronda, B) detalle de dos pinnas fértiles, C) rizoma y base de las frondas, D) escama

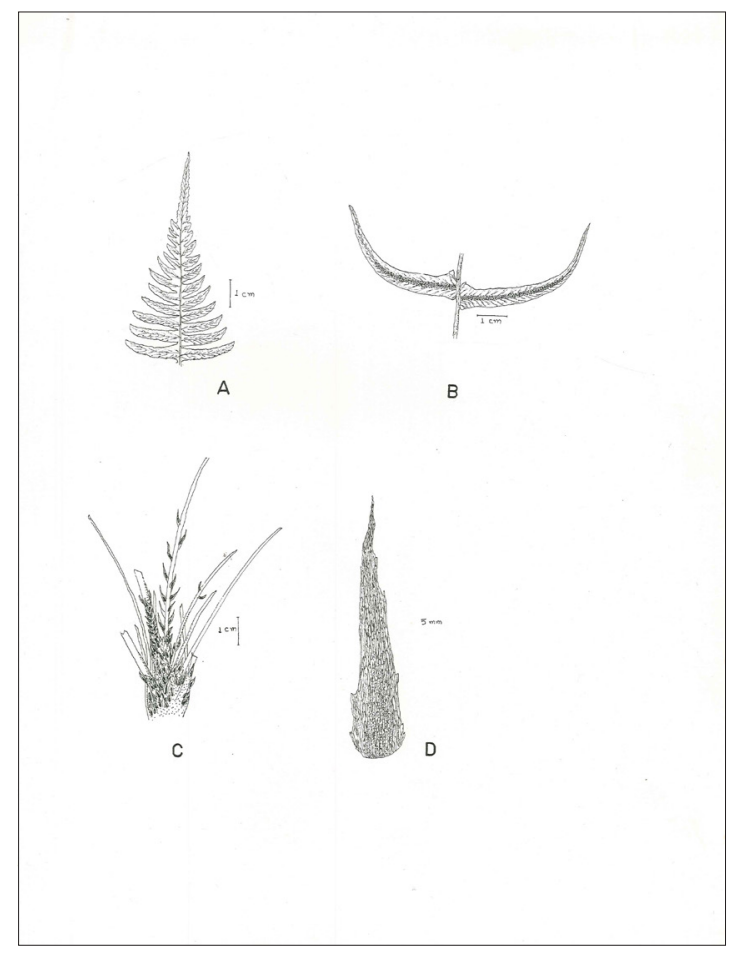

Fuente: elaboración propia.

Figura 9. Polystichum platyphylum: A) ápice de una fronda fértil, B) pinna mostrando la disposición de los soros, C) escama

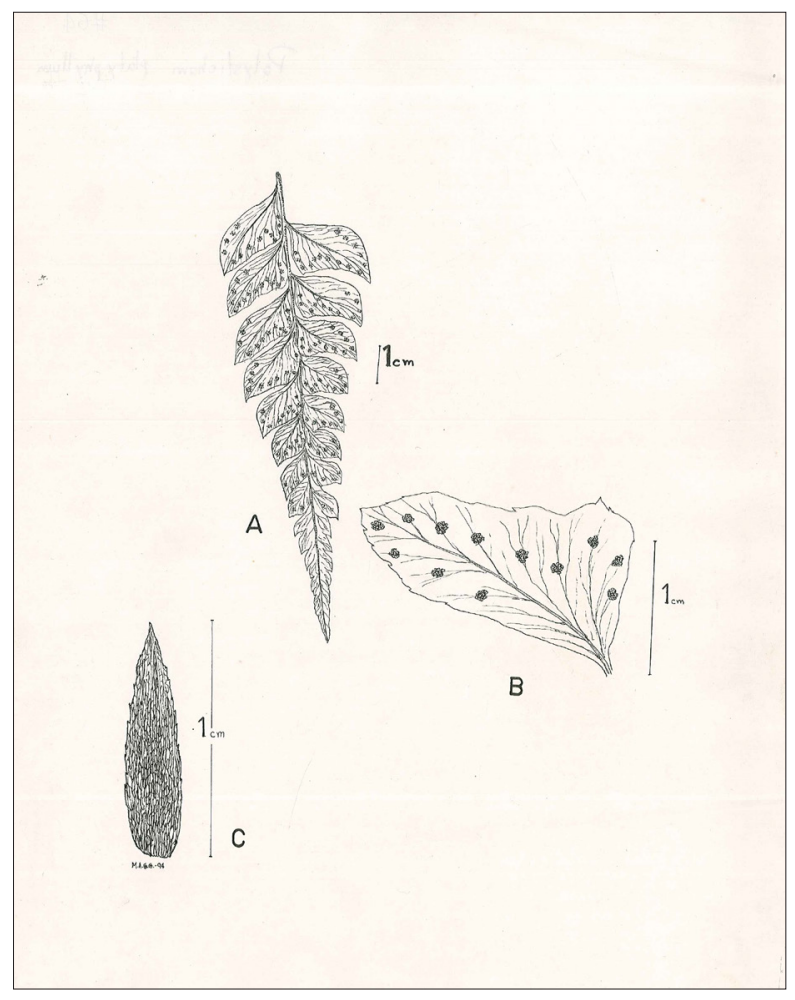

Fuente: elaboración propia. 


\section{Familia Lindsaeaceae C.Presl ex M.R. Schomb.}

Unas 200 especies componen esta familia de distribución pantropical, terrestres, infrecuentemente epilíticas o epífitas. Generalmente glabras de venas libres, hojas pinnadas una a tres veces, soros indusiados, marginales o submarginales, indusio extrorso.

\section{Lindsaea sp.}

Hierba terrestre, frondas $55 \mathrm{~cm}$, soro alargado sobre el borde arqueado de la pinna, con indusio, base del raquis color marrón, con canal central longitudinal, rizoma marrón rojizo, con escamas. Se da en zonas sombreadas y húmedas, con abundante hojarasca (figura 10).

Figura 10. Lindsaea sp.: A) ápice de una fronda, B) detalle de una pinna fértil, C) rizoma, D) escama

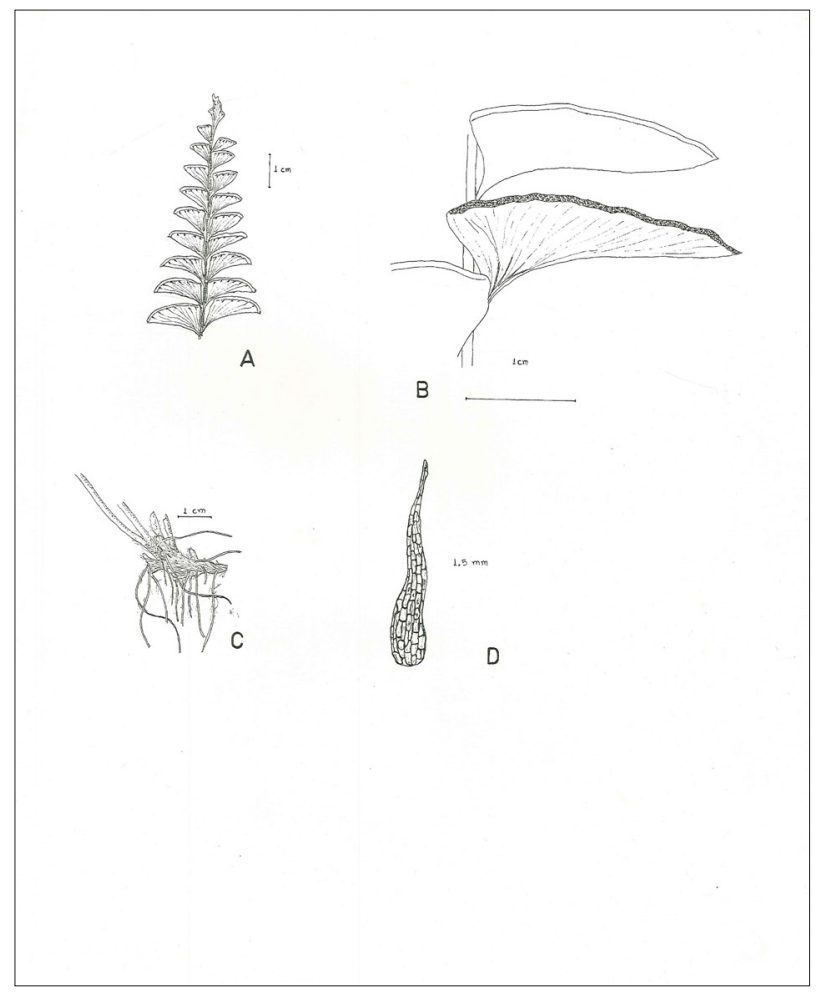

Fuente: elaboración propia

\section{Familia Marattiaceae Kaulf.}

Helechos terrestres, erectos o trepadores, con canales de mucílago en todo el cuerpo, micorrícicos, con aurículas en la base de los pecíolos, normalmente 1 a 3 pinnas o de hojas enteras. Presenta reproducción vegetativa notable.

\section{Danaea lucens A Rojas}

Hierba terrestre, de porte arbustivo, erecta, con rizoma erecto, grueso, de $5 \mathrm{~cm}$ de diámetro, en zona muy sombreada y húmeda del sotobosque, cerca de la quebrada Chontaduro.
Distribución: Chocó, Risaralda y Valle, entre 1.550 y $1.900 \mathrm{~m}$.

\section{Familia Polypodiaceae Berchtold \& J.C. Presl.}

Hierbas perennes terrestres, epífitas o epilíticas. Frondas mono o dimórficas, con pecíolo variadamente desarrollado, alado, con escamas o glabro, venación abierta, soros usualmente redondeados y prominentes pero pueden ser alargados. De distribución tropical, principalmente. Su clasificación genérica es complicada, algunos autores prefieren dividirla en dos o tres familias (Hennipman et al., 1990). 


\section{Campyloneurum sp.}

Hierba epífita. Frondas de hasta $50 \mathrm{~cm}$ por $1-2 \mathrm{~cm}$ de ancho, soros redondeados de $1 \mathrm{~mm}$ de diámetro al final de las venas, las cuales son abiertas, rizoma color marrón, con escamas, estas también presentes en las hojas, vena central de color amarillo pálido (figura 11).

\section{Pecluma divaricata (Fournier) Mickel \& Beitel}

Hierba terrestre, frondas de hasta 1,3 m. En zonas intervenidas en proceso de regeneración.

Distribución: Antioquia, Boyacá, Caldas, Cauca, Chocó, Cundinamarca, Meta, Nariño, Norte de Santander, Risaralda, Santander, Tolima y Valle, entre 350 y 3.000 m.

Figura 11. Campyloneurum sp.: A) rizoma y base de las frondas, B) detalle de una fronda fértil por el envés.

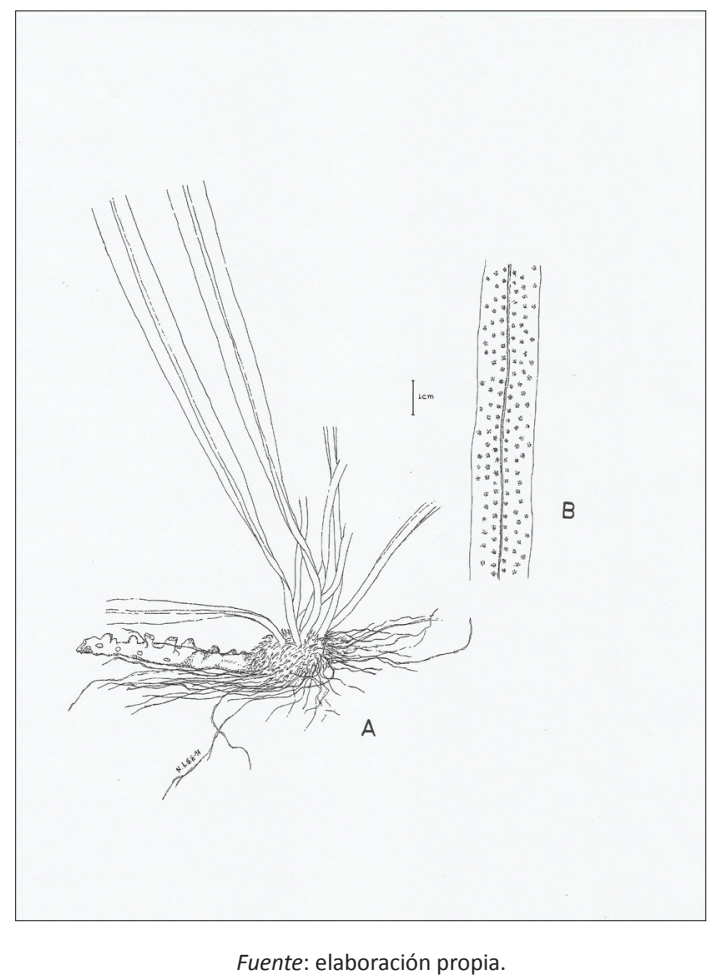

\section{Pleopeltis macrocarpa (Bory ex Willdenow) Kaulfuss}

Hierba epífita, fronda de $8-18 \mathrm{~cm}$ por $1-3 \mathrm{~cm}$, envés rojizo, soros redondeados, prominentes, a lado y lado de la vena central, haz con puntos vistosos. Rizoma profusamente esparcido en su forófito (figura 12).

Distribución: Amazonas, Antioquia, Boyacá, Caldas, Cauca, Cesar, Cundinamarca, Huila, Magdalena, Meta, Nariño, Norte de Santander, Putumayo, Santander, Tolima y Valle, entre 450 y 3.200 m.

\section{Pleopeltis remota (Desv.) A.R.Sm.}

Hierba epilítica, frondas de hasta $40 \mathrm{~cm}$, pinnas enteras de $0,8-0,9 \mathrm{~cm}$ por $0,5-0,9 \mathrm{~cm}$, de color verde claro, fusionadas hacia el ápice, soros redondeados de 2 $\mathrm{mm}$ de diámetro, caquis marrón oscuro, rizoma escamoso, muy ramificado (figura 13 ).

Distribución: Antioquia, Boyacá, Caldas, Cauca, Chocó, Cundinamarca, Huila, Magdalena, Putumayo, Santander y Valle, entre 1.300 y $2.800 \mathrm{~m}$.

\section{Polypodium fimbriatum Maxon}

Hierba epífita de 25-40 cm. Lámina dividida en pinnulas digitiformes, conectadas por alas en el raquis, envés de color rojo ladrillo, tricomas muy abundantes, soros en dos hileras pareadas a ambos lados de la vena central (figura 14).

Distribución: Antioquia, Cundinamarca, Meta y Valle, entre 350 y $3.000 \mathrm{~m}$. 


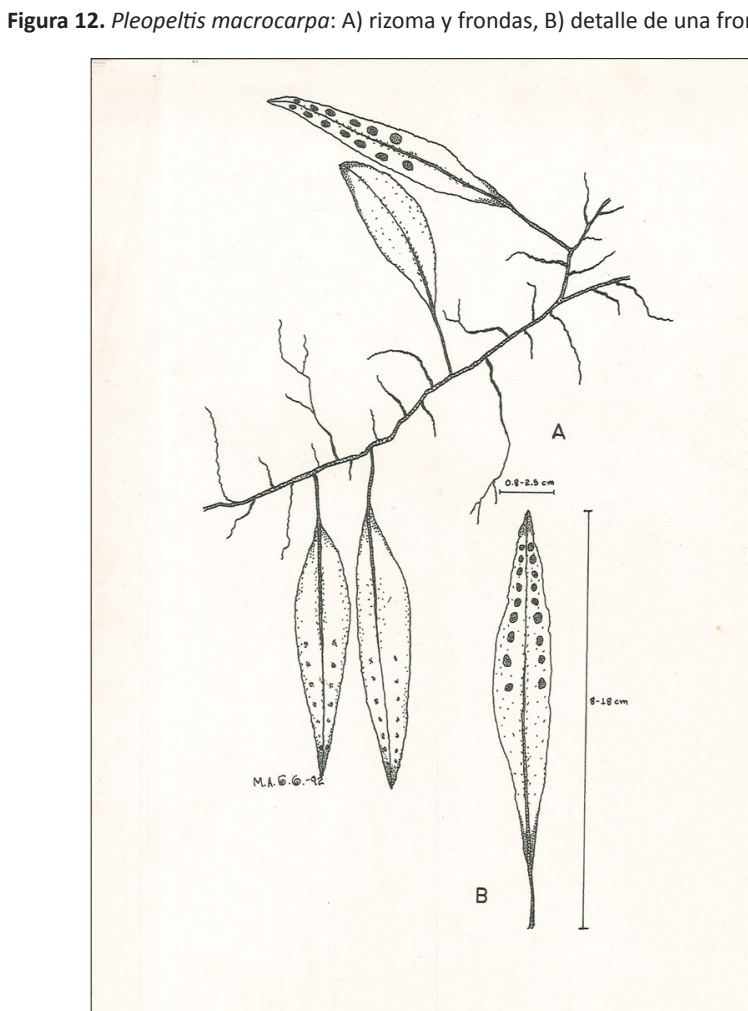

Fuente: elaboración propia.

Figura 13. Pleopeltis remota (Desv.) A.R.Sm.: A) extremo de una fronda fértil vista por el envés, B) vista panorámica de un rizoma y una fronda, C) detalle del rizoma

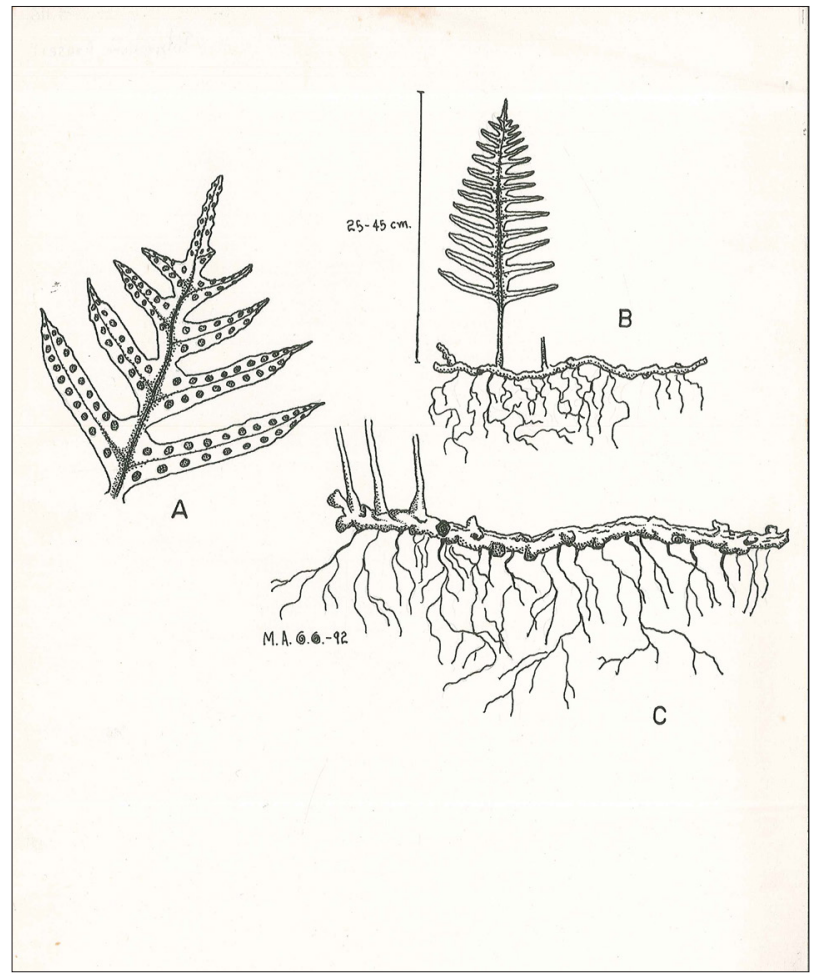

Fuente: elaboración propia.

1ITHE- Revista electrónica editada por la Facultad de Ciencias Naturales e Ingeniería de la UJTL 
Figura 14. Polypodium fimbriatum: A) base de las frondas y rizoma, B) ápice de una fronda, C) escama, D) detalle de una pinna por el envés

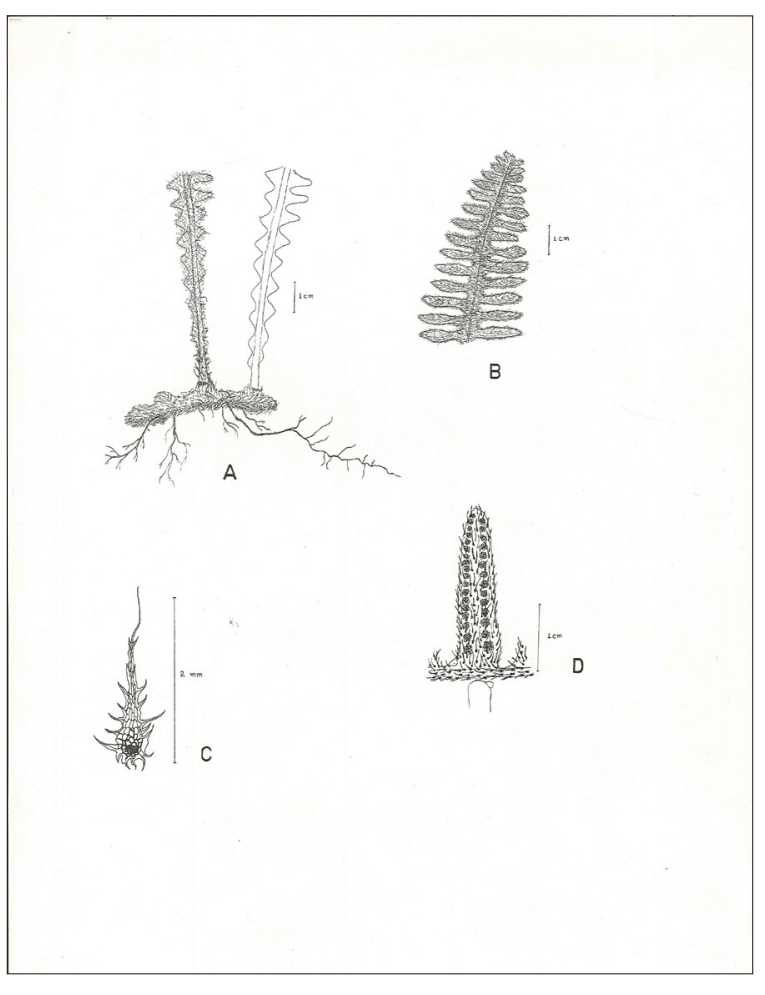

Fuente: elaboración propia.

\section{Serpocaulon fraxinifolium (Jacq.) A.R.Sm.}

Hierba hemiepífita, frondas de $80 \mathrm{~cm}$, pinnas $7-21 \mathrm{~cm}$ por 1-3 cm, haz verde oscuro, con puntos, soros redondeados de $1 \mathrm{~mm}$ de diámetro, entre las venas secundarias (figura 15).

Distribución: Antioquia, Boyacá, Cauca, Cesar, Chocó, Cundinamarca, Huila, Magdalena, Meta, Nariño, Norte de Santander, Putumayo, Quindío, Risaralda, Santander Tolima y Valle, entre 100 y $2.750 \mathrm{~m}$.

\section{Familia Pteridaceae E.D.M. Kirchn.}

Hierbas terrestres con algunas especies acuáticas, venas usualmente libres, soros lineales a lo largo de las venas, sin indusio, pero también pueden ser marginales. Son de distribución mundial pero centrada en los trópicos (Tryon, Tryon, \& Kramer, 1990).

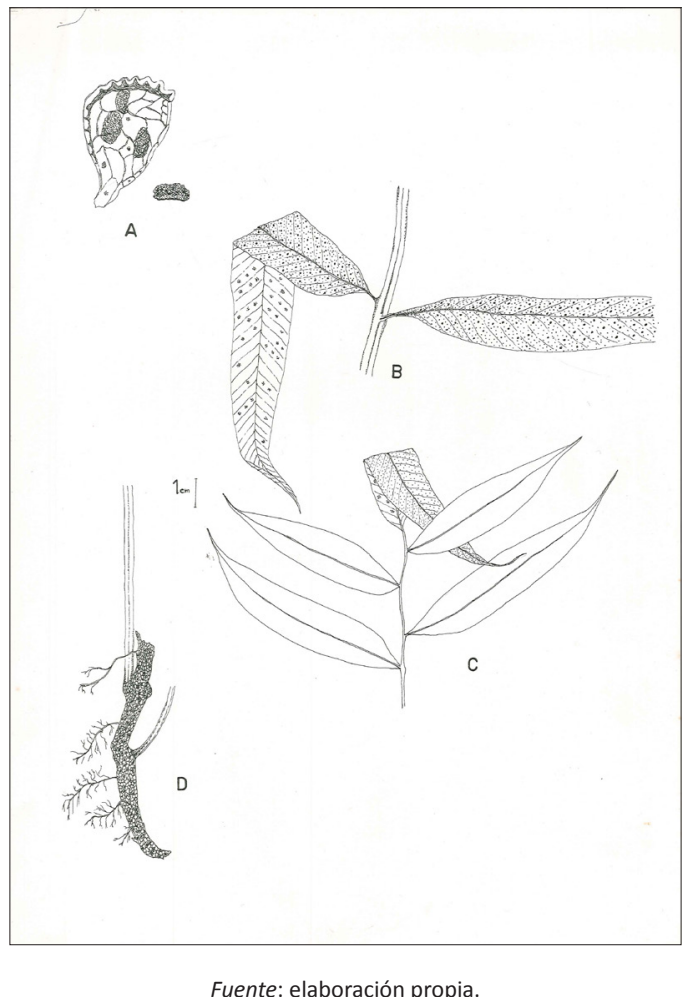




\section{Adiantum pulverulentum $\mathrm{L}$.}

Hierba terrestre, frondas de hasta $1 \mathrm{~m}$ de longitud, pinnas $7-20 \mathrm{~cm}$, raquis negro con canal central, con escamas amarillentas, pinnulas sésiles de 0,9-1,7 $\mathrm{cm}$, aserradas, con soros marginales alargados de 3-14 mm en su borde anterior. Hallada en zonas húmedas y sombreadas (figura 16).

Distribución: Amazonas, Antioquia, Bolívar, Caquetá, Cauca, Cesar, Chocó, Cundinamarca, Magdalena, Meta, Nariño, Putumayo, Quindío, Risaralda, Santander y Valle, desde el nivel del mar hasta $1.830 \mathrm{~m}$.

Figura 16. Adiantum pulverulentum: A) vista muy aumentada de un esporangio abierto, B) detalle de una pinna en una fronda fértil

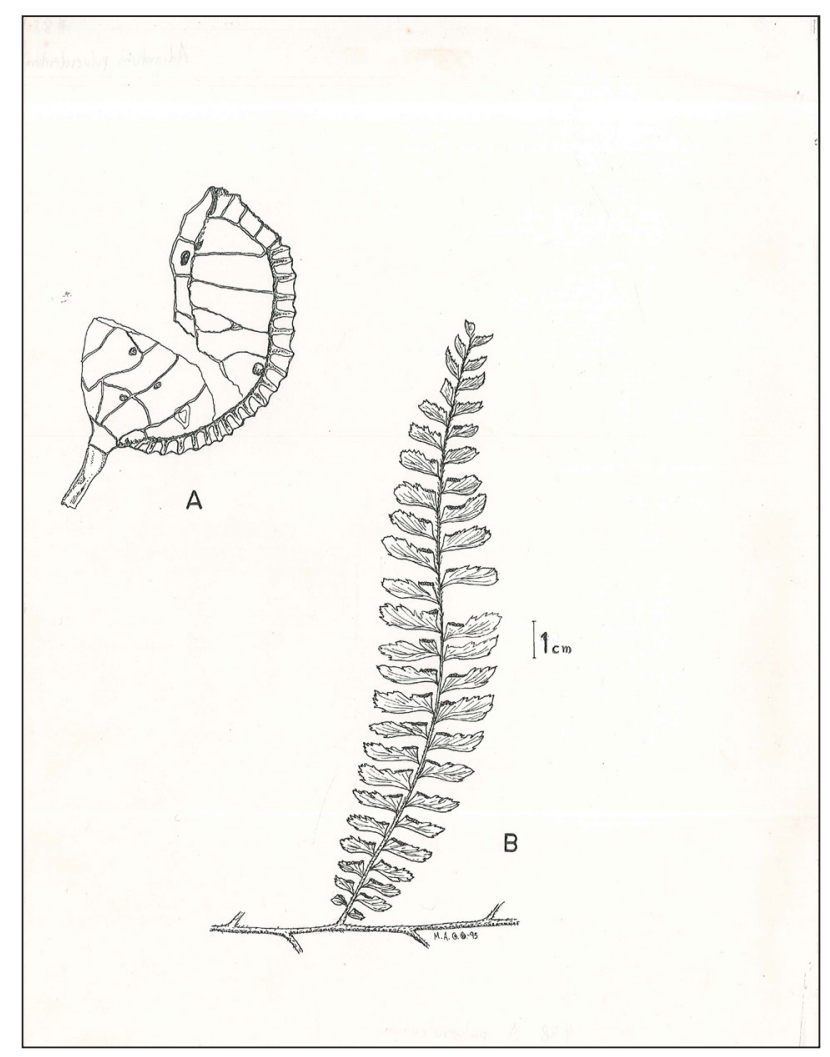

Fuente: elaboración propia.

\section{Familia Thelypteridaceae Ching ex Pic. Serm.}

Helechos terrestres, rara vez epífitos, con especies arbóreas, cuerpo escamoso, soros orbiculares o alargados sobre las venas. Familia con más de 1.000 especies, especialmente en los trópicos y zonas subtropicales (Smith, 1990).

\section{Thelypteris sp.}

Helecho arbóreo palmiforme de hasta $5 \mathrm{~m}$ de altura, con frondas de más de $1,5 \mathrm{~m}$ de longitud, cicatrices foliares conspicuas, abundantes escamas rojizas, soros acampanados y dispuestos en herradura cerca al borde foliar. Crece naturalmente en el sotobosque, en zonas sombreadas (figura 17).

Figura 17. Thelypteris sp.: A) detalle del final de una fronda por el haz, B) detalle de la disposición de los soros en el envés de una pinna fértil

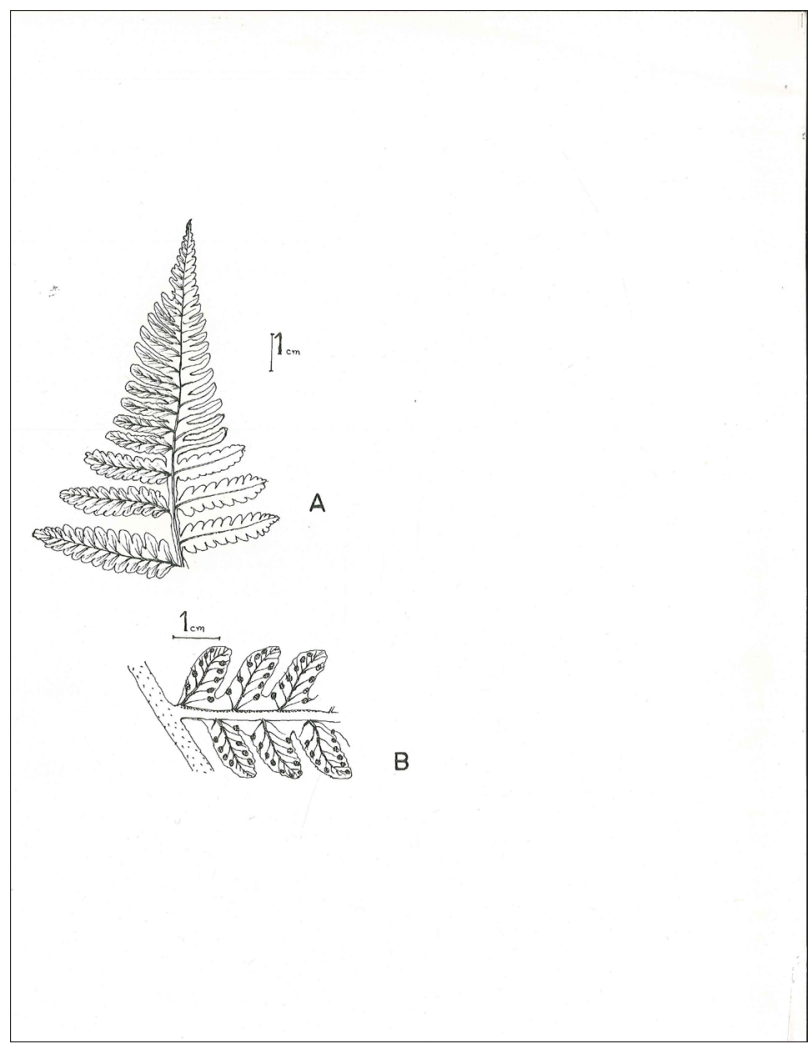

Fuente: elaboración propia. 


\section{DISCUSIÓN}

El bosque premontano de Pico de Águila presenta una notable diversidad vegetal a pesar de ser un ecosistema intervenido y muy cercano a una ciudad cosmopolita como Santiago de Cali. En efecto, Gamboa y Ramos (1995) presentan datos sobre su notable biodiversidad usando varios índices. En particular, la presencia de pteridófitas es notable, pues la existencia de 18 especies, prácticamente todas terrestres o epífitas de estratos bajos del bosque, se puede considerar un indicador de alta diversidad.

Es posible afirmar que al investigar el dosel del bosque, que en algunas zonas puede alcanzar $30 \mathrm{~m}$ de altura, se hallará nuevas especies. En este punto es importante aclarar que la sinonimia en los helechos es abundante, por lo que una recomendación para los investigadores en este grupo es que se actualicen constantemente en este asunto, teniendo en cuenta que varias de las especies reportadas aquí fueron inicialmente identificadas con nombres que han sido revaluados. El trabajo se continuará enfatizando en dos aspectos: el muestreo de estratos más altos del bosque y la búsqueda de información acerca de los usos de estas especies, tanto por parte de la pobladores de esta vereda como de otros lugares, con el fin de determinar su valor en posibles estudios de bioprospección.

\section{AGRADECIMIENTOS}

Los autores agradecen a la Primera Dama de la Botánica, la profesora María Teresa Murillo, quien orientó el proceso de recolección e identificación de los helechos al comienzo de este informe. A los profesores Jorge Eduardo Ramos y Philip Silverstone-Sopkin, del Herbario de la Universidad del Valle (cuvc), por su orientación y colaboración. Al profesor Carlos Parra, del Herbario Nacional Colombiano (COL), por permitir el acceso a los especímenes del col.

\section{REFERENCIAS}

Christenhusz, M. J. M., \& Chase, M. W. (2014). Trends and concepts in fern classification. Annals of Botany, 113(4), 571-594.

Christenhusz, M. J. M., Zhang, X.-C., \& Schneider, H. (2011). A linear sequence of extant families and genera of lycophytes and ferns. Phytotaxa, 19, 7-54.

Cronquist, A. (1981). An integrated system of classification of flowering plants. New York: Columbia University Press.

Corporación Autónoma Regional del Valle del Cauca [cVc]. (1983). Informe general sobre áreas del sistema de Parques Nacionales ubicados en la jurisdicción de la CVC. Palmira, Colombia: Corporación Autónoma Regional del Valle del Cauca, División Recursos Naturales.

Corporación Autónoma Regional del Valle del Cauca [cVc]. (2010). Informe final Convenio 256 de 2010. Corporación Autónoma Regional del Valle del Cauca (CVC), Grupo Sistemas de Información Ambiental, Grupo de Biodiversidad, Cali, Colombia: Corporación Autónoma Regional del Valle del Cauca.

Espinal, L. S. (1968). Visión ecológica del Departamento del Valle del Cauca. Cali: Universidad del Valle.

Gamboa-Gaitán, M. A., \& Ramos, J. E. (1995). Composición florística y diversidad vegetal de un bosque premontano en Los Farallones de Cali. En: Memorias del Primer Congreso Nacional sobre Biodiversidad (pp. 71-76). Instituto de Estudios del Pacífico, Universidad del Valle, Santiago de Cali, Colombia.

Gamboa-Gaitán, M. A. (1995). Contribución a la flora de Los Farallones de Cali. I. Vereda Pico de Águila (tesis de grado). Departamento de Biología, Universidad del Valle, Cali, Colombia.

García-Kirkbride, M. C. (1986). Biological evaluation of the Chocó biogeographic region in Colombia. Washington D. C.: World Wild Fund.

Hennipman, E., Veldhoen, P., Kramer, K. U., \& Price, M. G. (1990). Polypodiaceae. En Kubitzki, K. U. (Ed.). The families and genera of vascular plants. Volume I: Pteridophytes and gymnosperms (pp. 203-230). Berlín: Springer-Verlag.

Judd, W. S., Campbell, C. S., Kellog, E. A., Stevens, P. F., \& Donoghue, M. J. (2007). Plant systematics: $A$ phylogenetic approach ( $3^{\text {rd }}$ ed.). Sunderland, MA: Sinauer Associates. 
Kramer, K. U., Chambers, T. C., \& Hennipman, E. (1990). Blechnaceae. En Kubitzki, K. U. (Ed.). The families and genera of vascular plants. Volume I: Pteridophytes and gymnosperms (pp. 60-68). Berlín: Springer-Verlag.

Kramer, K. U., \& Green, P. S. (1990). Pteridophytes and Gymnosperms, volumen I. En: Kubitzki, K. U. (Ed.). The families and genera of vascular plants. Berlín: Springer-Verlag.

Kramer, K. U., Holttum, R. E., Moran, R. C., \& Smith, A. R. (1990). Dryopteridaceae. En: Kubitzki, K. U. (Ed.). The families and genera of vascular plants. Volume I: Pteridophytes and gymnosperms (pp. 101-144). Berlín: Springer-Verlag.

Kramer, K. U., \& Viane, R. (1990). Aspleniaceae. En: Kubitzki, K. U. (Ed.). The families and genera of vascular plants. Volume I: Pteridophytes and gymnosperms (pp. 52-57). Berlín: Springer-Verlag.

Mahecha-Vega, G. E., \& Echeverri-Restrepo, R. (1983). Árboles del Valle del Cauca. Bogotá: Progreso Corporación Financiera S. A.

Murillo, M. T. (1983). Usos de los helechos en Suramérica con especial referencia a Colombia. Bogotá: Instituto de Ciencias Naturales, Universidad Nacional de Colombia.

Parques Nacionales Naturales de Colombia [PNNC]. (2005). Plan de manejo 2005-2009 Parque Nacional Natural Farallones de Cali. Cali: Parques Nacionales Naturales de Colombia, Dirección Territorial de Suroccidente.

Parques Nacionales Naturales de Colombia [PNNC]. (2007, diciembre). Parques Nacionales Naturales de Colombia. Recuperado de http://www. parquesnacionales.gov.co/pnn/portel/libreria/ php/decide.php? patron $=01.010903 \& f_{\text {_ }}$ patron=01.0109

Pryer, K. M., Schneider, H., Smith, A. R., Cranfill, R., Wolf, P. G., Hunt, J. S., \& Sipes, S. D. 2001. Horsetails and ferns are a monophyletic group and the closest living relatives to seed plants. Nature, $409,618-622$.

Rangel-Ch, J. O., Aguilar-P, M., Sánchez-C, H., \& Lowy-C, P. (1995). Región costa pacífica. En
Rangel-Ch, J. O. (Ed.). Colombia diversidad biótica I (pp. 121-139). Bogotá: Instituto de Ciencias Naturales, Universidad Nacional de Colombia.

Raubeson, L. A., \& Jansen, R. K. (1992). Chloroplast DNA evidence on the ancient evolutionary split in vascular land plants. Science, 255, 1697-1699.

Sarria, S. (1993). Parque Nacional Natural Farallones de Cali. (Monografía). Cali: Corporación Autónoma Regional del Valle del Cauca/Fundación Protectora de las Cuencas, Procuencas.

Smith, A. R. (1990). Thelypteridaceae. En: Kubitzki, K. U. (Ed.). The families and genera of vascular plants. Volume I: Pteridophytes and gymnosperms (pp. 263-272). Berlín: Springer-Verlag.

Smith, A. R., Pryer, K. M., Schuettpelz, E., Korall, P., Schneider, H., \& Wolf, P. G. (20069. A classification for extant ferns. Taxon, 55(3), 705-731.

Takhtajan, A. (1997). Diversity and classification of flowering plants. New York, NY: Columbia University Press.

Tryon, R. M., Tryon, A. F., \& Kramer, K. U. 1990. Pteridaceae En: Kubitzki, K. U. (Ed.). The families and genera of vascular plants. Volume I: Pteridophytes and gymnosperms (pp. 230-256). Berlín: Springer-Verlag. 